\title{
Tacrolimus Anhydrous
}

National Cancer Institute

\section{Source}

National Cancer Institute. Tacrolimus Anhydrous. NCI Thesaurus. Code C76066.

Anhydrous from of tacrolimus, a macrolide isolated from Streptomyces tsukubaensis.

Tacrolimus binds to the FKBP-12 protein and forms a complex with calcium-dependent proteins, thereby inhibiting calcineurin phosphatase activity and resulting in decreased cytokine production. This agent exhibits potent immunosuppressive activity in vivo and prevents the activation of T-lymphocytes in response to antigenic or mitogenic stimulation. Tacrolimus possesses similar immunosuppressive properties to cyclosporine, but is more potent. 